\title{
The role of oxidative stress in hepatic ischemia- reperfusion injury: potential target for interventions in liver transplantation
}

\author{
Consuelo Orellana ${ }^{1}$, Rodrigo Villagrán ${ }^{1}$, Jonathan Zang $^{1}$ and Ramón Rodrigo ${ }^{2 *}$ \\ ${ }^{1}$ Medical students, Faculty of Medicine, University of Chile, Chile \\ ${ }^{2}$ Molecular and Clinical Pharmacology Program, Institute of Biomedical Sciences, Faculty of Medicine, University of Chile, Independencia 1027, Santiago, Chile
}

\begin{abstract}
Liver transplantation is the definitive therapy for most patients with end-stage liver failure. During this surgical procedure, hepatic ischemia-reperfusion is an unavoidable phenomenon known to be involved in graft injury, often resulting in postoperative complications and liver dysfunction. Although the pathophysiology behind ischemia reperfusion injury (IRI) comprises various mechanisms, oxidative stress (OS) has been recognized as a key factor. The aims of this review are to provide an updated overview of the role of OS in liver IRI, providing some bases for therapeutic interventions based on counteracting the OS-related mechanism of injury and thus suggesting novel possible strategies in the prevention of IRI in liver transplants.
\end{abstract}

\section{Introduction}

Orthotopic liver transplantation (OLT) has become a lifesaving procedure for patients with end-stage liver disease or hepatocellular carcinoma. In this complex surgical process, reperfusion of the hypoxic tissue is an unavoidable phenomenon that aggravates the ischemic insult, causing harmful ischemic-reperfusion injury (IRI). Liver IRI is associated with postoperative graft dysfunction, transplant rejections and may increase the risk of organ failure [1]. This situation is a major problem, especially considering that there is a shortage of liver donors. Indeed, in 2018, 13,295 patients in the USA were waiting for a liver transplant, but only 8,250 procedures were performed, indicating a shortage of about 5,000 per year [2]. This plight has promoted the extension of donor organ criteria, so that suboptimal grafts, such as older, steatotic, dead-brain or non-heart-beating donors can be used for liver transplantation, as well as organs that have been subjected to prolonged periods of warm and cold storage [3]. However, these organs are particularly susceptible to IRI as a result of damage throughout the processes of procurement, preservation and surgery [4-8]. In summary, IRI not only contributes to the organ shortage (as organs might be deemed too damaged for the transplant) but also may damage remote vital organs [9], incur multiple organ failures, graft non-function, and acute or chronic rejection [10]. Despite the obvious clinical relevance of these data, the mechanisms accounting for organ IRI have not been elucidated [11,12]. Nevertheless, oxidative stress (OS) has been recognized as a key factor [13]. The aims of this review are to present an updated outlook of the role of OS in liver IRI, providing some foundations for therapeutic interventions based on counteracting the OS-related mechanism of injury and thus suggesting novel possible strategies for prevention of IRI in liver transplants.

\section{Role of oxidative stress in liver transplantation}

Reactive oxygen species (ROS) are physiologically generated in an intrinsic way in every aerobic organism. In this process, mitochondria are the most important source of their production [14]. ROS comprises oxygen free radicals, such as hydroxyl radicals, peroxyl radicals, and superoxide anion, along with non-radicals like hypochlorous acid, hydrogen peroxide and ozone [15]. Those compounds are able to cause damage to DNA as well as peroxidation of unsaturated fatty acids in cellular membranes, thus disrupting cellular integrity. Furthermore, lipid peroxyl radicals react with other lipids, nucleic acids and proteins, heightening damage [3]. To prevent this from occurring, there are endogenous defense mechanisms against ROS, which include enzymatic antioxidant defenses (such as superoxide dismutase (SOD), catalase (CAT), and glutathione peroxidase (GSH-Px)), and nonenzymatic compounds (beta-carotene, ascorbate, glutathione (GSH) and a-tocopherol). However, if ROS production increases enough to overwhelm the antioxidant defense system the cell undergoes oxidative stress. This can also happen if the cellular antioxidant systems are depleted [16]. During a liver transplant, the interruption of blood inflow followed by reperfusion produces an abrupt increase in ROS, disrupting balance and causing oxidative stress and generally inflammatory progressions. It has been shown that ROS are able to both trigger and modulate the allograft failure following OLT, by producing microvascular dysfunction and parenchymal injury [17]. Moreover, during the early stage of reperfusion, Kupffer cells (KC) are activated, modifying their morphology together with increasing ROS production [18]. In experimental models, ROS released from KC contribute to release inflammatory mediators, trigger the process of

${ }^{\star}$ Correspondence to: Ramón Rodrigo, Molecular and Clinical Pharmacology Program, Institute of Biomedical Sciences, Faculty of Medicine, University of Chile, Independencia 1027, Santiago, Chile, E-mail: rrodrigo@med.uchile.cl

Key words: ischemia-reperfusion, liver transplantation, oxidative stress, reactive oxygen species

Received: April 19, 2019; Accepted: April 26, 2019; Published: April 30, 2019 
neutrophils recruitment and even are able to induce diverse signaling pathways, culminating in cell death due to necrosis and/or apoptosis. All these pathophysiological events result in circulatory disturbances responsible for enhancing liver damage. [19-22]. At the cellular level, the mechanisms of ROS in liver IRI involve an increased expression of proinflammatory genes (TNF- $\alpha$, IL- 6 , IL- 8 or cell adhesion molecules) [11], a response mediated by the induction of transcription factors such as nuclear factor kappa-B (NF- $\mathrm{kB}$ ) and protein activator factor-1 (AP-1) [23]. In addition, it should be considered other mechanisms as the direct cell injury by protein oxidation and degradation, lipid peroxidation and DNA damage [24], direct induction of cell death (both apoptotic and necrotic) [25] and inactivation of antiproteases [24]. Early effects of IRI are shown on Figure 1.

\section{Antioxidants and liver ischemia-reperfusion injury}

Firstly, there are compounds with a direct antioxidant effect, such as vitamin $\mathrm{E}$ and $\mathrm{C}$. Vitamin $\mathrm{E}$ is a lipid-soluble antioxidant capable of removing peroxyl radicals [26]. It also enhances the levels of GSH and ameliorates the $\alpha$-tocopherol/lipid ratio in the liver [27], normalizes the 8-epi-prostaglandin F2 $\alpha$ [28] and avoids the activation of NF- $\kappa B$ [29], constituting itself as the most powerful antioxidant [30]. Studies in obese mice have shown that administration of $\alpha$-tocopherol before a period of ischemia-reperfusion decreases mortality [31]. In cirrhotic patients, vitamin $\mathrm{E}$ concentrations were significantly lower than in control subjects. Nevertheless, after liver transplantation, the levels of vitamin $\mathrm{E}$ remain altered, even in the late post-operative period [30]. In addition, vitamin C (also known as ascorbic acid) is a hydrophilic antioxidant, unstable in water solutions. Its derivative ascorbic acid-2 glucoside (AA-2G) is a better therapeutic option, due to its greater stability and less tendency to oxidative degradation [32,33]. In trials with mice, it was reported that the administration of AA-2G decreased apoptosis in the sinusoidal cells after a transplant with preservation at subzero non-freezing temperature, allowing better preservation of hepatocytes [33]. A study conducted by Soltys et al. found that supplementation with a-tocopherol and ascorbic acid enhances GSH levels, improves the a-tocopherol/lipid ratio and also leads to increases in catalase (CAT) activity in livers of obese rats. In healthy rats, similar improvements are achieved [27]. Indeed, it has been reported that treatment with ascorbic acid alone also would be protective against IRI [34]. Secondly, there are compounds that can act as indirect antioxidants by inducing low increases in ROS levels; polyunsaturated omega-3 fatty acids (n-3 PUFAs) as alpha linolenic acid (ALA) [precursor of eicosapentaenoic acid (EPA) and docosahexaenoic acid (DHA)], [35] are essential lipids that must be obtained from the diet. It has been shown that these compounds have a wide range of mechanisms and several effects such as anti inflammatory actions [36,37] and endothelial cell protection [38-40]. A meta-analysis evidenced that DHA administration decreases postoperative complications after partial hepatectomy and reduces hospital stays [41]. Furthermore, in mice, n-3 PUFAs improved regeneration and function after partial hepatectomy [42], decreased necrosis and malondialdehyde levels (an oxygen radical-induced product of lipid peroxidation), enhanced GSH levels, CAT and SOD activities and attenuated proinflammatory cytokines production [43].

\section{Novel therapeutic approaches}

During the last years, a series of therapeutic strategies based on counteracting the OS-related mechanism of injury has been proposed to prevent IRI in OLT. These strategies comprise ischemic pre-conditioning, hydrogen-rich solution, Peroxiredoxin-6, propofol, proteasome inhibitors, among others, being tested in mice and/ or humans with some promising results, such as an improvement of the redox imbalance, a decrease of apoptosis and a reduction in the inflammatory process [44-48]. Therefore, the modulation of oxidative stress by reinforcing the antioxidant defense system, would be an effective therapeutic target to improve the performance of liver transplantation. Furthermore, it has been hypothesized that antioxidants would influence the allograft function after OLT [27]. Thus, antioxidants supplementation would be a safe and low-cost therapeutic approach that, based on the aforementioned studies and OS-related mechanisms in IRI, could be a cost-effective strategy feasible to improve the outcome of patients undergoing a liver transplantation. Previously, this strategy was used in ameliorating the effects of ischemia/reperfusion in hearts of patients subjected to cardiac surgery with extracorporeal circulation. The intervention was based on the

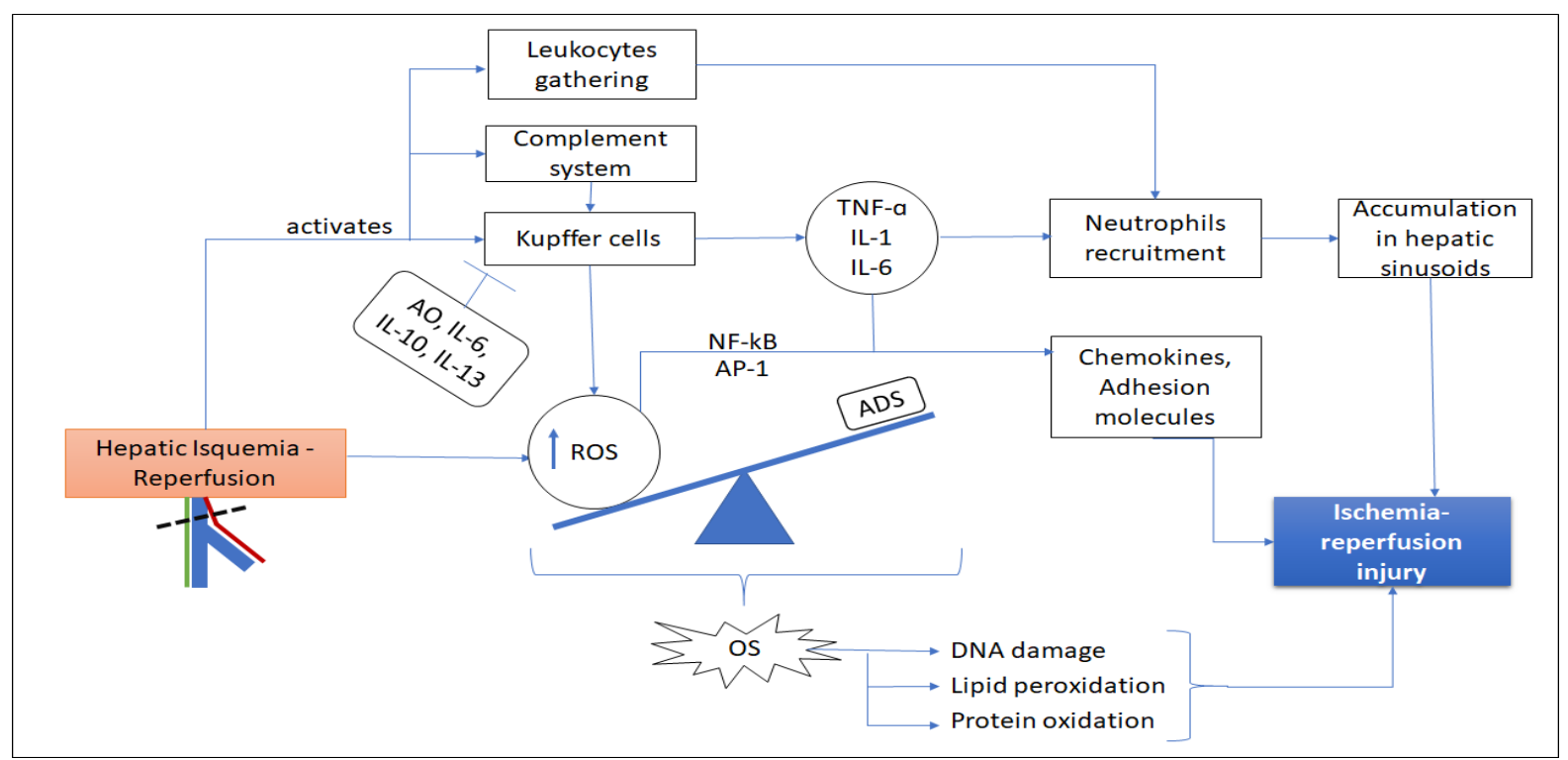

Figure 1. Early effects of ischemic-reperfusion injury. AO: antioxidants; IL: interleukin; TNF- $\alpha$ : tumor necrosis factor; ROS: reactive oxygen species; OS: oxidative stress; ADS: antioxidant defense system; NF-kB: Nuclear factor kappa-B; AP-1: protein activator factor-1. Source: own elaboration 
synergistic effect between vitamins ( $C$ and $E$ ) and n-3 PUFAs (EPA and DHA in a 1:2 ratio). OS amelioration was accompanied by a decreased myocardial vulnerability to the oxidative challenge known to happen during ischemia-reperfusion [49]. This experience could serve to lay the foundations of future clinical research regarding other phenomena linked to IRI, such as liver dysfunction after transplantation.

\section{Concluding remarks}

The IRI following OLT remains a major problem in clinical practice, due to its involvement in post-operative complications, graft dysfunction, transplant rejections and increased risk of organ failure. Nevertheless, oxidative stress has been recognized as a key factor. Consequently, evidence suggests that novel therapies, such as those based on antioxidant defense system reinforcement, might improve the patient's clinical outcome after this procedure. The administration of vitamin $C$ and $E$ plus n-3 PUFAs generate a synergistic effect that could provide a useful, low risk and economic alternative treatment in the near future. Nevertheless, the mechanisms behind organ IRI are not fully understood, leading to highlight the importance to continue investigating in order to clarify the role of all the factors involved in the protective mechanism and design protocols accounting for more precise and complete therapeutic strategies.

\section{References}

1. Zhai Y, Petrowsky H, Hong JC, Busuttil RW, Kupiec-Weglinski JW (2013) Ischaemia-reperfusion injury in liver transplantation-from bench to bedside. Nat Rev Gastroenterol Hepatol 10: 79

2. http://optn.transplant.hrsa.gov/data/

3. Gutteridge JM, Halliwell B (2000) Free radicals and antioxidants in the year 2000. A historical look to the future. Ann N Y Acad Sci 899: 136-147. [Crossref]

4. McCormack L, Dutkowski P, El-Badry AM, Clavien PA (2011) Liver transplantation using fatty livers: always feasible? Journal of hepatology 54: 1055-1062.

5. Chu MJ, Premkumar R, Hickey AJ, Jiang Y, Delahunt B, et al. (2016) Steatotic livers are susceptible to normothermic ischemia-reperfusion injury from mitochondrial Complex-I dysfunction. World J Gastroenterol 22: 4673-4684. [Crossref]

6. Weiss S, Kotsch K, Francuski M, Reutzel-Selke A, Mantouvalou L, et al. (2007) Brain death activates donor organs and is associated with a worse I/R injury after liver transplantation. Am J Transplant 7: 1584-1593.

7. McKeown CM, Edwards V, Phillips MJ, Harvey PR, Petrunka CN, et al. (1988) Sinusoidal lining cell damage: the critical injury in cold preservation of liver allografts in the rat. Transplantation 46: 178-191. [Crossref]

8. Caldwell-Kenkel JC, Currin RT, Tanaka Y, Thurman RG, Lemasters JJ (1989) Reperfusion injury to endothelial cells following cold ischemic storage of rat livers. Hepatology 10: 292-299.

9. Chan KC, Lin CJ, Lee PH, Chen CF, Lai YL, et al. (2008) Propofol attenuates the decrease of dynamic compliance and water content in the lung by decreasing oxidative radicals released from the reperfused liver. Anesth Analg 107: 1284-1289.

10. Fellström B, Aküyrek L, Backman U, Larsson E, Melin J, et al. (1998) Postischemic reperfusion injury and allograft arteriosclerosis. Transplant Proc 30: 4278-4280.

11. Lentsch AB, Kato A, Yoshidome H, McMasters KM, Edwards MJ (2000) Inflammatory mechanisms and therapeutic strategies for warm hepatic ischemia/reperfusion injury. Hepatology 32: 169-173.

12. Zhai Y, Busuttil RW, Kupiec-Weglinski JW (2011) Liver ischemia and reperfusion injury: new insights into mechanisms of innate-adaptive immune-mediated tissue inflammation. Am J Transplant 11: 1563-1569.

13. Connor HD, Gao W, Nukina S, Lemasters JJ, Mason RP, et al. (1992) Evidence that free radicals are involved in graft failure following orthotopic liver transplantation in the rat--an electron paramagnetic resonance spin trapping study. Transplantation 54 : 199-204.

14. Kohen R, Nyska A (2002) Invited review: Oxidation of biological systems: oxidative stress phenomena, antioxidants, redox reactions, and methods for their quantification. Toxicol Pathol 30: 620-650.
15. Li S, Tan HY, Wang N, Zhang ZJ, Lao L, et al. (2015) The role of oxidative stress and antioxidants in liver diseases. Int J Mol Sci 16: 26087-26124.

16. Hensley K, Robinson KA, Gabbita SP, Salsman S, Floyd RA (2000) Reactive oxygen species, cell signaling, and cell injury. Free Radic Biol Med 28: 1456-1462. [Crossref]

17. Towfigh S, Heisler T, Rigberg DA, Hines OJ, Chu J, et al. (2000) Intestinal ischemia and the gut-liver axis: an in vitro model. J Surg Res 88: 160-164. [Crossref]

18. Li J, Li RJ, Lv GY, Liu HQ (2015) The mechanisms and strategies to protect from hepatic ischemia-reperfusion injury. Eur Rev Med Pharmacol Sci 19: 2036-2047. [Crossref]

19. Busuttil RW, Tanaka K (2003) The utility of marginal donors in liver transplantation. Liver Transpl 9: 651-663.

20. Selzner N, Rudiger H, Graf R, Clavien PA (2003) Protective strategies against ischemic injury of the liver. Gastroenterology 125: 917-936.

21. Omar R, Nomikos I, Piccorelli G, Savino J, Agarwal N (1989) Prevention of postischaemic lipid peroxidation and liver cell injury by iron chelation. Gut 30: 510514. [Crossref]

22. Mizunuma K, Ohdan H, Tashiro H, Fudaba Y, Ito H, et al. (2003) Prevention of ischemia-reperfusion-induced hepatic microcirculatory disruption by inhibiting stellate cell contraction using rock inhibitor1. Transplantation 75: 579-586.

23. Zwacka RM, Zhang Y, Zhou W, Halldorson J, Engelhardt JF (1998) Ischemia reperfusion injury in the liver of BALB/c mice activates AP-1 and nuclear factor ?B independently of I?B degradation. Hepatology 28: 1022-1030.

24. Jaeschke H (2000) Reactive oxygen and mechanisms of inflammatory liver injury. $J$ Gastroenterol Hepatol 15: 718-724. [Crossref]

25. Rüdiger HA, Clavien PA (2002) Tumor necrosis factor a, but not Fas, mediates hepatocellular apoptosis in the murine ischemic liver. Gastroenterology 122: 202-210.

26. Terentis AC, Thomas SR, Burr JA, Liebler DC, Stocker R (2002) Vitamin E oxidation in human atherosclerotic lesions. Circulation research 90: 333-339.

27. Soltys K, Dikdan G, Koneru B (2001) Oxidative stress in fatty livers of obese Zucker rats: rapid amelioration and improved tolerance to warm ischemia with tocopherol Hepatology 34: 13-18.

28. Laight DW, Desai KM, Gopaul NK, Änggård EE, Carrier MJ (1999) F2-isoprostane evidence of oxidant stress in the insulin resistant, obese Zucker rat: effects of vitamin E. Eur J Pharmacol 377: 89-92.

29. Nakamura T, Goto M, Matsumoto A, Tanaka I (1998) Inhibition of NF-〈kappaB transcriptional activity bylalpha-tocopheryl succinate. Biofactors 7: 21-30.

30. Augusto V, Rodrigues A, Reis G, Silveira A, de Castro e Silva O, et al. (2014) Evaluation of Oxidative Stress in the Late Postoperative Stage of Liver Transplantation. Transplant Proc 46: 1453-1457.

31. Corradini SG, Micheletta F, Natoli S, Iappelli M, Di Angelantonio E, et al. (2005) High preoperative recipient plasma $7 ß$-hydroxycholesterol is associated with initial poor graft function after liver transplantation. Liver transplantation 11: 1494-1504.

32. Yamamoto I, Suga S, Mitoh Y, Tanaka M, Muto N (1990) Antiscorbutic activity of L-ascorbic acid 2-glucoside and its availability as a vitamin $\mathrm{C}$ supplement in normal rats and guinea pigs. J Pharmacobiodyn 13: 688-695.

33. Matsukawa H (2000) Ascorbic acid 2-glucoside prevents sinusoidal endothelial cell apoptosis in supercooled preserved grafts in rat liver transplantation. Transplant Proc 32: 313-317.

34. Ozaki M, Fuchinoue S, Teraoka S, Ota K (1995) The in vivo cytoprotection of ascorbic acid against ischemia/reoxygenation injury of rat liver. Archives of biochemistry and biophysics 318: 439-445.

35. Lavie CJ, Milani RV, Mehra MR, Ventura HO (2009) Omega-3 polyunsaturated fatty acids and cardiovascular diseases. $J$ Am Coll Cardiol 54: 585-594.

36. Wiktorowska-Owczarek A, Berezinska M, Nowak J (2015) PUFAs: Structures, Metabolism and Functions. Advances In Clinical And Experimental Medicine 24: 931941

37. Ferrucci L, Cherubini A, Bandinelli S, Bartali B, Corsi A, et al. (2006) Relationship of plasma polyunsaturated fatty acids to circulating inflammatory markers. JCEM 91: 439-446.

38. Zúñiga J, Cancino $M$, Medina $F$, Varela $P$, Vargas R, et al. (2011) N-3 PUFA supplementation triggers PPAR-a activation and PPAR-a/NF-?B interaction: antiinflammatory implications in liver ischemia-reperfusion injury. PloS one 6: e28502. 
39. Xue B, Yang Z, Wang X, Shi H (2012) Omega-3 polyunsaturated fatty acids antagonize macrophage inflammation via activation of AMPK/SIRT1 pathway. PloS one 7: e45990.

40. Manzi L, Costantini L, Molinari R, Merendino N (2015) Effect of Dietary?-3 Polyunsaturated Fatty Acid DHA on Glycolytic Enzymes and Warburg Phenotypes in Cancer. BioMed Research International 2015: 1-7.

41. Zhang C, Chen B, Jiao A, Li F, Wang B, et al. (2017) The benefit of immunonutrition in patients undergoing hepatectomy: a systematic review and meta-analysis. Oncotarget 8: 86843 .

42. Marsman HA, De Graaf W, Heger M, Van Golen RF, Ten Kate FJW, et al. (2013) Hepatic regeneration and functional recovery following partial liver resection in an experimental model of hepatic steatosis treated with omega-3 fatty acids. Br J Surg 100: 674-683.

43. Li Z, Zhao F, Cao Y, Zhang, J, Shi P, Sun X., et al. (2018) DHA attenuates hepatic ischemia reperfusion injury by inhibiting pyroptosis and activating PI3K/Akt pathway. Eur J Pharmacol 835: 1-10.
44. Jaeschke H (2003) Molecular mechanisms of hepatic ischemia-reperfusion injury and preconditioning. Am J Physiol Gastrointest Liver Physiol 284: G15-G26.

45. Uto K, Que W, Sakamoto S, Zhong L, Li XK, et al. (2017) Hydrogen Rich Solution Attenuates Cold Ischemia-Reperfusion Injury in Rat Liver Transplantation. Transplantation 101: S18.

46. TTu Q, Xiong Y, Fan L, Qiao B, Xia Z, et al. (2016) Peroxiredoxin 6 attenuates ischemiaand hypoxia-induced liver damage of brain-dead donors. Mol Med Rep 13: 753-761.

47. Yao W, Han X, Zhang Y, Guan J, Ge M, et al. (2018) Intravenous Anesthetic Protects Hepatocyte from Reactive Oxygen Species-Induced Cellular Apoptosis during Liver Transplantation In Vivo. Oxidative medicine and cellular longevity 2018: 1-10.

48. Alexandrova A, Petrov L, Georgieva A, Kessiova M, Tzvetanova E, et al. (2008) Effect of MG132 on proteasome activity and prooxidant/antioxidant status of rat liver subjected to ischemia/reperfusion injury. Hepatol Res 38: 393-401.

49. Rodrigo R, Korantzopoulos P, Cereceda M, Asenjo R, Zamorano J, et al. (2013) A randomized controlled trial to prevent post-operative atrial fibrillation by antioxidant reinforcement. $J$ Am Coll Cardiol 62: 1457-1465.

Copyright: (2019 Orellana C. This is an open-access article distributed under the terms of the Creative Commons Attribution License, which permits unrestricted use, distribution, and reproduction in any medium, provided the original author and source are credited. 